\title{
CT-GUIDED TREPHINE EXCISION OF AN INFECTED ILIAC PIN SITE AFTER PELVIC FRACTURE
}

\author{
P. F. PARTINGTON, \\ R. J. MONTGOMERY, \\ G. P. NAISBY
}

CT-guided biopsies have been used in both soft tissues and when necessary (Ahlström and Åström 1993). Percutabone and trephines have been used for cortical penetration neous resection of osteoid osteoma by trephine has been

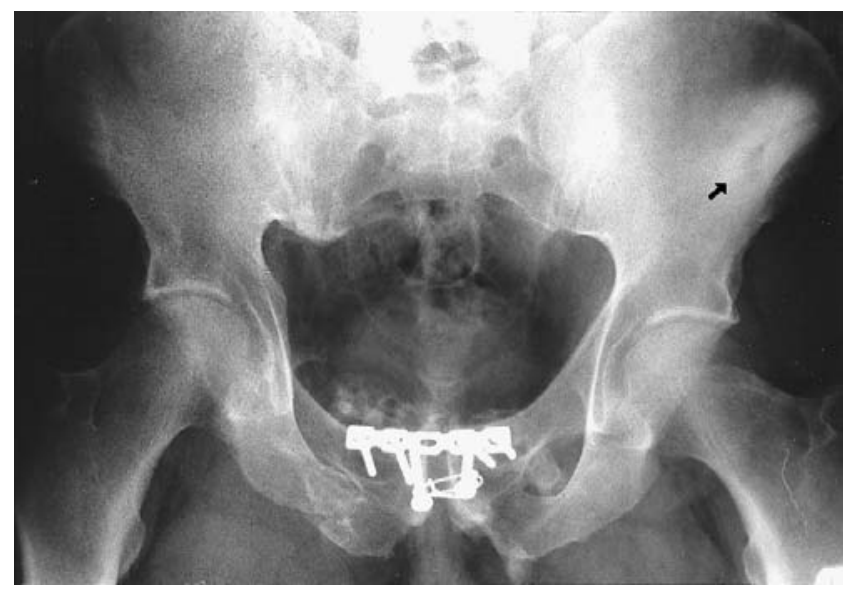

Fig. 1

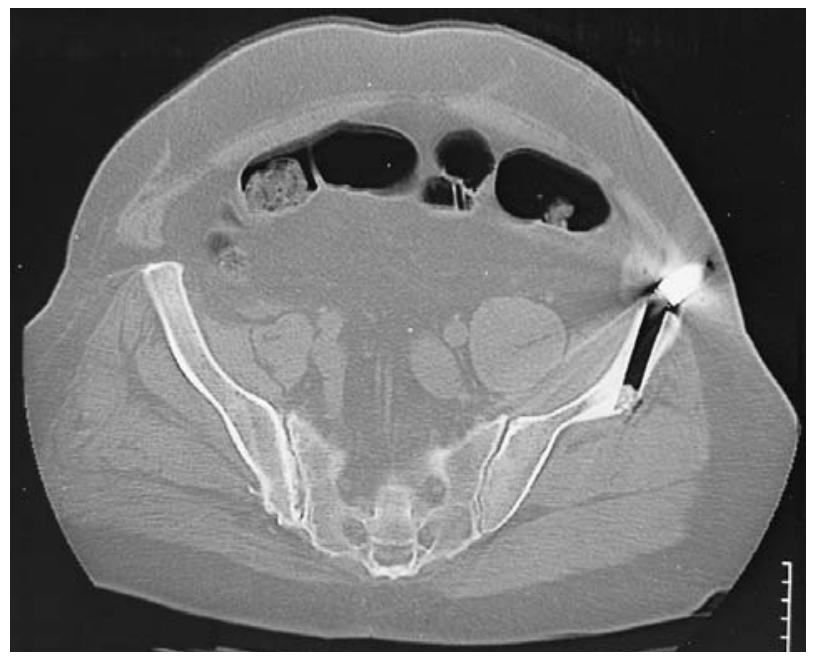

Fig. 3

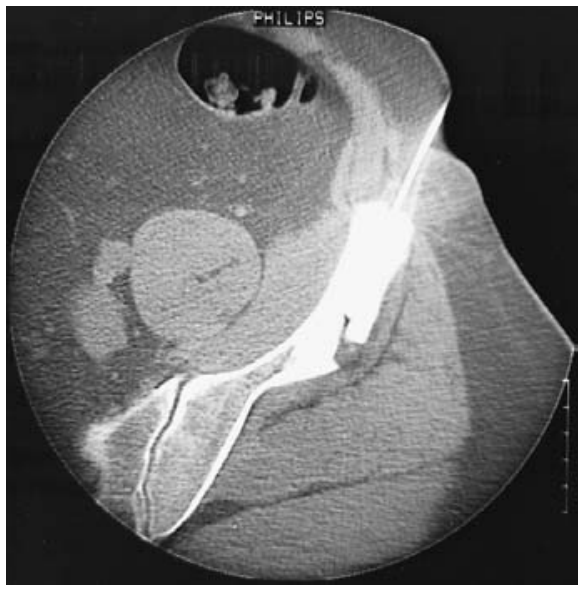

Fig. 2

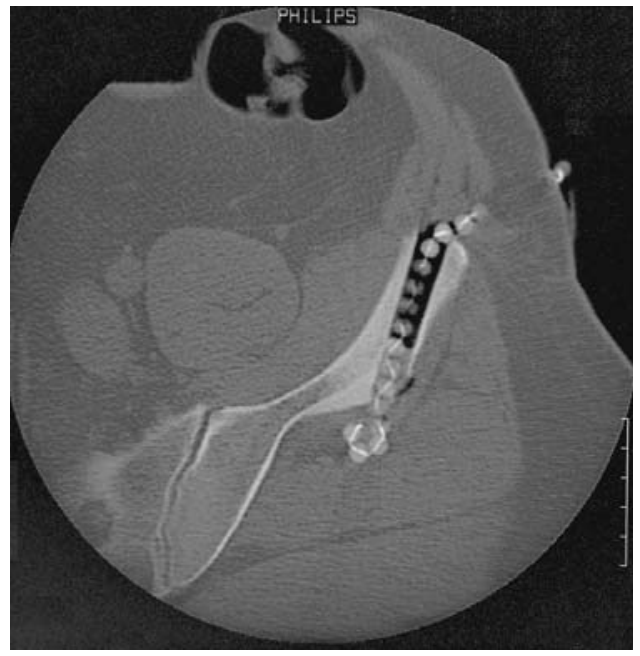

Fig. 4
P. F. Partington, FRCS, Senior Orthopaedic Registrar

Sunderland District General Hospital, Kayll Road, Sunderland SR4 7TP, UK.

R. J. Montgomery, FRCS, Consultant Orthopaedic Surgeon

Middlesbrough General Hospital, Ayresome Green Lane, Middlesbrough TS5 5AZ, UK.

G. P. Naisby, FRCR, Consultant Radiologist

South Cleveland Hospital, Marton Road, Middlesbrough TS5 3BW, UK.

Correspondence to Mr R. J. Montgomery.

(C)1996 British Editorial Society of Bone and Joint Surgery 0301-620X/96/4R62 \$2.00

J Bone Joint Surg [Br] 1996;78-B:668-9.

Received 30 May 1995; Accepted 12 July 1995 described (Assoun, Railhac and Bonnevialle 1993).

We report the CT-guided trephine excision of a chronically infected pin site after external fixation of a pelvic fracture, thus avoiding more major surgery with its associated pain, morbidity and inpatient stay.

Case report. A 32-year-old man sustained a closed pelvic disruption after being crushed by heavy machinery. There was disruption of the pubic symphysis and the right sacroiliac joint with fractures of the ipsilateral pubic rami and some cephalad displacement of the hemipelvis. We obtained reduction and fixation by a combination of inter- 
nal fixation of the pubic symphysis and external fixation of the iliac crests.

The inferior pin site on the left side became infected with Staphylococcus aureus which did not resolve after two courses of appropriate antibiotics and careful daily cleaning. The fixator was removed 13 weeks after application. Twenty months after the injury intermittent discharge continued and plain radiography indicated chronic osteomyelitis (Fig. 1). CT confirmed the extent of the infection and suggested that the outer table of the ilium at the tip of the pin track had been breached.

A trephine set was manufactured to dimensions determined by the CT scan (John Burdon Medical Engineering, North Yorkshire, UK). Under general anaesthesia and CT guidance, a guide wire was used to locate the pin track through the sinus and then advanced along its length (Fig. 2). A small incision was made around the wire and a softtissue sheath and an obturator were advanced down to the ilium. A trephine was passed over the obturator and a core of infected bone was removed (Fig. 3). This was continued until the outer cortex had been breached. A string of gentamicin-loaded beads was then passed through the softtissue sheath and down the resulting track in the ilium (Fig. 4).

The patient was mobilised 24 hours after operation. He was kept in hospital for four days and given high-dose intravenous antibiotics and then discharged home on oral medication. One week after operation gradual removal of the beads was begun. After eight months, his wound remains dry and there are no signs of recurrence of the infection.

No benefits in any form have been received or will be received from a commercial party related directly or indirectly to the subject of this article.

\section{REFERENCES}

Ahlström KH, Åström KG. CT guided bone biopsy performed by means of a coaxial biopsy system with an eccentric drill. Radiology 1993;188:549-52.

Assoun J, Railhac JJ, Bonnevialle P. Osteoid osteoma: percutaneous resection with CT guidance. Radiology 1993;188:541-7. 